\title{
Goya, el Grabado y la Técnica
}

JUAN MANUEL UGARTE ELESPURU.

Sea también nuestro más agradecido aplauso, para la Asociación Española de Artistas Grabadores que han reunido ésta importantísima muestra del grabado. Para las entidades nacionales auspiciadoras de su exposición en Lima y para la Dirección del Museo de Reproducciones de la Universidad Mayor de San Marcos que la acogen.

Es a ellos a quienes debemos esta singular oportunidad doblemente escepcional, tanto por la calidad que la amerita, como por lo raro en nuestro medio.

No estamos habituados al trato continuo con el arte de grabar, porque el grabado tiene en nuestro páís éscasos cultivadores. Se puede decir, sin pecar de exagerados, que su difusión es nula, poco menos que general su desconocimiento y mayor aún, la falta de noticia sobre sus técnicas y procedimientos.

Ni la estampa aislada, ni el libro ilustrado, son productos generalizados entre nosotros. Carecemos, en este aspecto del Arte, de una tradición nacional que nos obligue, de solicitud que nos impulse, de producción actual que nos interese.

Al parecer, nuestros artistas no se sienten mayormente atraídos hacia la estampa grabada, como medio de expresión en sus quehaceres creativos.

Sin embargo, en las esferas populares provincianas, se practicó, Y se practica aún, el grabado en madera a la fibra, como auxiliar de las modestas publicaciones pueblerinas. Pero son estos grabados elementales manifestaciones de un conocimiento primario, que no ha podido alcanzar categoría, ni crea interés permanente.

Por ello, debemos considerar el arribo de ésta interesantísima muestra del grabado español, como utilísima cooperación para formar un criterio, tanto como un aleccionador ejemplo de laboriosa y sabia 
dedicación a tan noble actividad artística, cuyos sabrosos frutos tenemos hoy a nuestro alcance, para regalo y docencia de nuestro paladar estético.

Pero es de temer que tan importante acontecimiento no sea debidamente aquilatado en toda su trascendencia. Acallados los aplausos tras las brillantes disertaciones; apaciguada la curiosidad diletante, calmos los trajines de la novedad, queda un espacio de silenciosa contemplación en el espectador bisoño. Es el instante en el que se sitúa ante la estampa contagiado del entusiasmo apologético de críticos y conferenciantes, resonantes aún en sus oídos las exaltadas voces laudatorias, va a buscar por sí mismo la confirmación de lo escuchado, a valorar "per se", las estampas, sin más guía que su juicio personal. Peligroso momento ese. Los rotundos adjetivos pierden su capacidad convincente, surgen desde la niebla del desconocimiento, la duda, la perplejidad y finalmente el aburrimiento.

Contribuyen al desencanto muchos factores, entre los que se cuentan principalmente la cantidad de piezas que solicitan simultáneamente su atención y su casi uniforme monocromía, la pequeña dimensión que exige proximidad, recogimiento, casi diría, intimidad en la gustación, que sólo puede surgir del captar calidades, cuya belleza estriba en tenues matices de factura.

Si todas las artes, para ser apreciadas debidamente, exigen un gusto depurado o un instinto orientado por sucesivas experiencias: el grabado, que no cuenta en sú abono con lastimpresionantes sugerencias del color, ni la elocuencia arrebatadora del arabesco de gran estilo, pide para su gustación, más que en cualquier otra arte, al conocedor. Aquel conocedor que sepa descubrir en el limitado espacio de la lámina, la callada musicalidad de su lenguaje, comprender y desentrañar las exquisiteces de sus logros, los vericuetos de sus soluciones técnicas.

Pues bien, ello sólo se puede alcanzar teniendo noticia, aunque sea somera, de su naturaleza, conociendo sus procedimientos, sabiendo de sus maneras.

Goya, el grabado y la técnica, es el título de ésta disertación en provecho de una comprensión más clara, vamos a invertir el orden, empezaremos por la técnica, seguiremos con el grabado y terminaremos con Goya.

Mucho me temo que voy a ofender, al intentar un análisis a vuelo de noticia sobre la técnica, del grabado, a los que aquí me están escuchando y son conocedores o profesionales, les pido disculpas; pero creo que esto es fundamentalmente necesario para poder fundamentar 
mis razones cuando entre en el terreno del enjuiciaminto y la comparación. De otro modo podría no ser entendido o al menos mal interpretado.

Dos son las características primordiales que diferencian la estampa grabada del cuadro pintado o la hoja dibujada. Una es su naturaleza indirecta, pues el artista no labora sobre el papel en que vemos la imagen expuesta, sino que ésta, es la resultante de la transportación por medio de la presión, de un origen trabajado sobre la superficie de una plancha de metal, taco de madera, u otro material que sirva al mismo fin.

La segunda característica es su multiplicidad, pues con la misma plancha se pueden sacar miles de copias idénticas.

En todos los casos el grabado es trabajado sobre la superficie pulida de una plancha, en la que la herramienta del grabador dibuja determinados trozos. Plancha que se somete luego al entintado, se le superpone una hoja de papel $\mathrm{y}$ ambos, papel y plancha, se pasan por la presión de un tórculo o prensa, el cual hace pasar a su vez por impresión, la tinta contenida en la plancha, a la superficie del papel.

Dos son también las ramas principales de este tronco inicial. Una es aquella en que la superficie a trabajar es ahondada por la herramienta, de modo que al entintar por medio de rodillo, que corre paralelo a la superficie, éste deposita la tinta tan sólo en ella, quedando en consecuencia lo ahuecado, libre de entinte.

Al imprimir, todo aquello que fuera hondura aparecerá como blanco en el papel; quien tomarálitinta solamente de las partes superficiales que no fueron rebajadas. Este es el grabado en madera, linóleo - metal, trabajado en ese temperamento.

En la otra familia, el procedimiento es inverso. La herramienta incidirá la superficie de la plancha con el fin de que la tinta sea introducida en los surcos dejados. El entintado se realiza, no con rodillo, sino ponceando, para que la tinta penetre en las honduras. Luego se limpia cuidadosamente la superficie, para que ésta no macule la blancura del papel, que sólo debe ser teñido por la tinta contenida en el rayado. Ocasionalmente se recurre a dejar partes mal limpiadas en la superficie, para que proporcione en la impresión, veladuras y efectos. Este es un recurso algo ilícito, muy usado en los tiempos modernos.

Pertenece a esta manera la llamada puntaseca, procedimiento en el cual la mano del grabador presiona por medio de un punzón de acero la superficie de la plancha, de modo que del regulado de estas presiones, queden incisiones más o menos pronunciadas, que se traducirán luego en valores de densidad o delicadeza. 


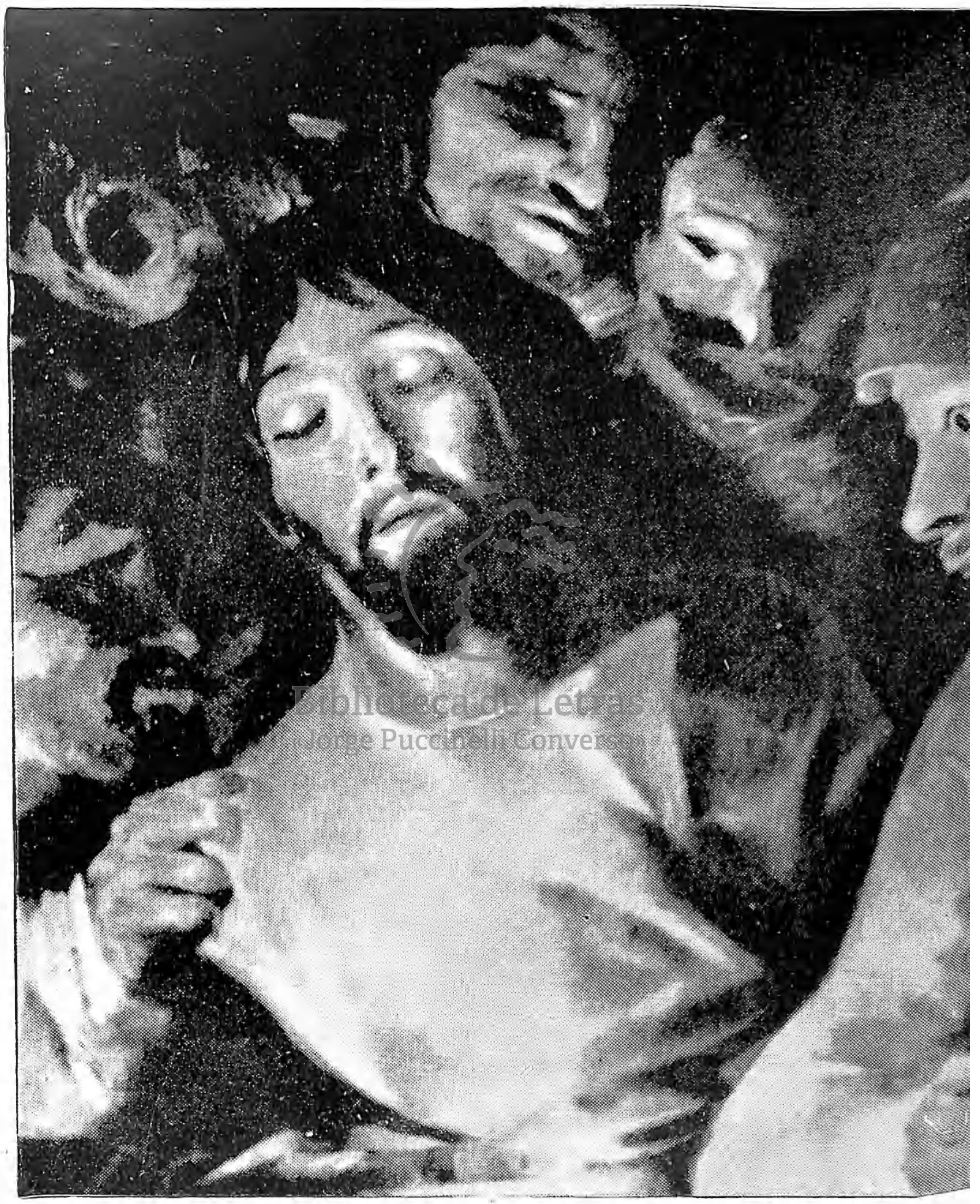

EL PRENDIMIENTO DE CRISTO (Detalle). 


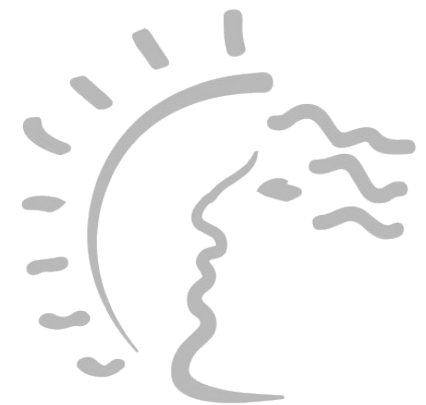

Biblioteca de Letras "Jorge Puccinelli Converso» 
En aguafuerte, se usa la misma herramienta de incisión, pero en este caso, ella dibuja apenas rascando la superficie del metal, previamente protegida de un barniz adhoc. De esta manera, levanta tan sólo dicho barniz, sin afectar mayormente el metal subyacente. Terminado el conjunto de trazos, se sumerge la plancha en un compuesto de ácido nítrico y agua, llamado aguafuerte, el cual ataca al metal en todos los lugares que no están protegidos por la cobertura del barniz.

El entre cruce de los sucesivos rayados, el tiempo de los baños; y diversos recursos de rebarnizados, nuevos rayados y baños de diferentes duraciones, labran en la superficie metálica, un entramado de surcos, finos y débiles unos, hondos y anchos otros, que al entintar la plancha por el ponceado y luego limpiarla cuidadosamente, dejará en la impresión una infinita y rica variedad de valores que van desde el blanco inmaculado del papel hasta los negros más intensos.

La técnica del aguafuerte ha variado poco desde su aparición. Si bien se han agregado otros procedimientos, derivados del uso del ácido mordienta, como la Aguatinta, la cual consiste en espolvorear sobre la plancha de metal, una resina, de modo que la cubra uniformemente. Sometida luego al calor, los granos de resina se funden y endurecen. Al sumergir la plancha en el ácido, éste atacará al metal al través de los espacios intergranulares de la resina.

Cubriendo la plancha con pinceladas de barniz protector, se preservarán a voluntad del mordido las partes que se desea y por la combinación de sucesivas mordidas y protecciones se logra al entintar diversos grados de negrura desdel el blanco puro/al negro profundo. Combinada con el rayado del aguafuarte y como su colaborante, se usa esta técnica. Aunque también puede presentarse sola y por sí misma.

Lá manera Negra es una técnica en la que se labra, por graneado a fondo, la plancha, hasta dejar un tono negro total. Luego, con el auxilio de un pulidor, se va debilitando los negrores por raspado, obteniéndose así grises de transición y hasta blancos fuertes, si el raspado es a fondo.

Semeja esta técnica a un dibujo sobre papel, que se ennegreciera a carbón para luego sacar con el borrador valores a voluntad.

En el grabado a color, son varias las planchas que se usan, una para cada color. Al imprimirse sucesivamente sobre una misma lámina, dejan en ella cada cual el suyo, separados o superpuestos. Se consigue así un conjunto variado de tonos y valores, que luego se refuerzan con la última impresión en negro.

La litografía no es estrictamente grabado pues en ella ni se incide ni se rebaja, sino que se fija el dibujo de un lápiz graso en una 
piedra o superficie metálica adecuada. Por medio del ácido nítrico clorhídrico y agua gomosa, se insensibiliza la superficie, la cual lavada; sólo tendrá la tinta de la impresión en las partes que el trazo grasoso del lápiz impidió la acción insensibilizadora.

Para la litografía a color se procede como en los demás grabados, por varias planchas.

La Monotipia consiste, tal como su nombre lo dice, en un solo ejemplar, resultante de dibujar o pintar sobre la plancha la imagen y someterla sin más trámite a la presión con lo cual pasará lo pintado al papel. Sobre los efectos conseguidos, aveces se superpone la impresión de punta seca o aguafuerte, para dar a éstos efectos de color, sin recurrir a los engorrosos trajines de las planchas múltiples. Es éste un método libre, que participa del grabado y la monotipia, pero no es extrictamente ni uno ni otro.

En el grabado a Buril, no interviene el ácido mordiente, su principio es similar al de la punta seca, pues es la mano y sólo la presión de la mano del grabador, la que determina la fuerza y expresión de las líneas. Se diferencia de la punta seca en el uso del buril, herramienta corta, de mango aperillado y hoja de acero, cuya punta está cortada en diamante o bisel. Hay diversas formas de buriles, cada una eficaz para los efectos correspondientes.

Naturalmente, se preguntarán Uds. Si todo es grabado, a qué obodece esa variedad de procedímientos más aún si constatamos que unas maneras son más dificultosas que las etras?

La diferencia de los procedimientos, además de las preferensias temperamentales de cada grabador, obedece principalmente a necesidades de vehículo expresivo y calidades de textura.

Todos los procedimientos no son aptos para todos los temas. La voluntad de forma necesita de determinados resultados objetivos para sus fines. Expliquémonos.

La punta seca, por ejemplo, deja un trazo aterciopelado mórbido en el papel, el buril, en cambio, destaca la precisión lineal con una virtualidad descriptiva que no permite los efectos de contrastes demasiados intensos. En los grabados a Buril, aun en aquellos en que la mano del grabador fuerza el procedimiento con un juego variado de valores en el manejo de sombras y luces, siempre campea una claridad que delata la original blancura del papel soportante.

En el entrecruzado de las virgulillas, el buril impone contención al temperamento, limitación al nervio creativo, sentido de mesura a la vehemencia. 
Oficio ímprobo, anterior en su aparición a las otras maneras de grabar el metal, fué muy cultivado antaño, cuando el artífice concienzudo era la base del artista creador.

Su práctica, decae con la aparición del aguafuerte, a fines del siglo XVI. Queda relegado al uso de los grabadores de reproducción. En esas limitadas manos artesanas, llegará a sombrosas posibilidades de minucia, perderá su pureza primigenia, hasta languidecer en perfecciones de aburrimiento.

Lo sustituye en la preferencia de los creadores, el agua-fuerte procedimiento más flexible que se adapta mejor a las urgencias del temperamento barroco.

Con el ocaso del buril, queda el aguafuerte como el señor indiscutido del arte grabador. Más rico en posibilidades de su factura, sus calidades lineales presentan con la irregularidad de sus márgenes desigualmente mordidos por el ácido, una sensualidad plástico-objetiva inigualadas por ningún otro procedimiento. Sirve maravillosamente a la sensibilidad moderna desembarazada del rigor tectónico de la armonía lineal renacentista, le permite, en cambio sumergirse en el revuelto mar de la apasionada interpretación del universo visible.

Su amplísimo registro, posibiliza todas las aventuras de la luz y las sombras, relega al papel soportante a la simple misión de encuadre, le arranca todas las características de su inerte naturaleza; lo violenta hasta convertirlo en titilante luz o lo rechaza hasta las últimas posibjlidades de la penumbra.

Jinete en este corcel fogosoi el grabador se lanza a la conquista de todos los horizontes, de todas las fantasías. Los recursos de su técnica desenvuelta y liberal le permite la expansión sin control, casi sin límites.

Dos espíritus irreconciliables se oponen en estos dos procedimientos. De un lado, en el buril, el método y la claridad, el oficio paciente y el rigor conscientes, como moderantes contrapesos, a los impulsos de la creación.

Del otro, en el Aguafuerte, la violenta y lebérrima voluntad de factura, el gusto por todo lo que hay de particular en la interpretación. La voluptuosidad en el manejo de un elemento caprichoso, el ácido mordiente, al que hay que reducir a dócil servicio.

Pero no quisiera que mis palabras se interpretasen como que el aguafuerte es cosa librada a la casualidad.

Ahí está el barniz protegiendo la plancha, el punzón dibujando sobre la morena superficie del cobre barnizado, el ácido mordiente listo para emplear su ataque corrosivo. 
Son tres fuerzas cuyas potencias ciegas nos ofrecen sus servicios. Cada una de ellas tiene su poder y su misión: juntas, controladas, dirigidas van a provocar la aparición del milagro. Es verdad que dejan margen a la casualidad. Pero así están ellas, cada una celosa de su fuerza dispuestas a oponerse más de lo necesario en la resistencia o pasarse inmoderadamente destructoras en el ataque. Por encima de ellas, como un taumaturgo alquimista trajinando el contenido misterioso de sus probetas, el grabador debe manejarlas; soltándolas en la justa medida en que cada una sea necesaria, desviando su congénita avidez de predominio, regulando su ansiosa voluntad de aniquilación.

En cuanto este caos aparente sea provocado, guiado y medido por el grabador, los resultados serán aceptables. De otro modo, las opacas sombras del fracaso o las desvaídas luces de la inepcia, campearán irresolutas e irresueltas en la estampa abortada.

Cada procedimiento genera su estilo, como cada propósito escoge su procedimiento. Cada época histórica también, elige el estilo y procedimiento, que más le conviene.

La humanidad está siempre en trance de alumbramiento, cuando decae en algún lugar, resurge en otro, favorecida por el juego cambiante de las circunstancias. Cuando los factores determinantes se dán ila oportunidad aparece!

El genio de la creación humana puede cambiar de país, de época, con ello cambiará de nombre y de aspecto, tal vez también de naturaleza. Puede ser Ciencia y Literatura en un momento. Música en otro, Escultura o Pintura. Todas son facetas de unar misma fuente generatriz. Un equilibrado juego de balanzas mantiene las fuerzas en ascenso o descenso. Unas en la luz, mientras otras fermentan esperando su oportunidad en la entraña.

En cambio en otros lugares, hasta el pasado inmediato liminarias, el fulgor se debilita, languidece, se va conviertiendo en sombras $y$ remedo de lo que fuera antes plenitud y verdad.

En determinado momento de la historia y en determinado lugar del espacio geográfico, el Demiurgo derrama, generosamente, circunstancias favorables para ésta o aquella forma de creación. Surge inmediatamente, ahí mismo, un vigoroso movimiento, nacen los individuos especialmente dotados para esa tarea, encuentran la posibilidad de su desarrollo.

Es el representativo. Aquel a quien los dioses han designado en la ancha base de sus congéneres, para situarlo en la aguda cima. Si individualidad reuniera en un fajo, los anhelos, las creencias, las pasiones, todas las características de su grupo y su tiempo. 
En el lenguaje del grabado hay tres hombres que cumplieron esta misión. Pertenecen a tres tiempos equidistantes, a tres momentos diferentes. Son ellos: Alberto Durero en la Alemania casi renacentista. Rembrandt van Ryn en la Holanda casi barroca. Francisco Goya en la España casi contemporánea.

El primero en el acontecer es Durero, hombre aupado sobre dos siglos; el XV que finiquitaba y el XVI que nacía. Entre dos tiempos de la historia la Edad Media que se iba, y el Renacimiento que triunfaba.

Nace en 1471, muere en 1528. Este alemán de Nuremberg es espiritualmente todavía un medioeval, sabemos que el Renacimiento tarda en impregnar a la Germania. Pero fué por su educación, completada en Italia, un renacentista.

Su arte vive ésta dualidad. El lleva al través de los Alpes su acusiosa voluntad alemana de saber, absorbe en los centros de la culta Italia de ese tiempo, todo lo que convino y nada más; pero nada menos. Retorna al terruño, llevando en su alforja los libros de medida del fraile Paccioli, en su espíritu el sentimiento de la claridad y la armonía esa "Divina Proporción" que es la mayor gloria del Renacimiento en Italia. Pero también la mística de la concepción integral y numérica del universo, microcosmos.

Practicó el grabado sobre metal, también la madera, con el buril aplica la técnica imperante en su medio, que era robusta y viviento tradición en los burgos gemánicos.

Consiste esta técnica en un meticuloso incidido de prodigiosa rogularidad en el trazado, siempre dentro de las posibilidades del procedimiento, respetando escrupulosamentelanverdad del papel, $\sin$ forzarlo con claro-oscuros intensos, discreto en la acentuación de los contrastes.

Durero grabador, supera en habilidad técnica y fuerza creadora a todos sus contemporáneos. Ni antes ni después, nadie le iguala en la pureza de su dicción ajustada perfectamente a las necesidades de su mensaje.

Pasma analizar trozo a trozo esa maravillosa calidad táctil de sus estampas. La finura y precisión de su mano para recrearse en las más sutiles relaciones de presión y dirección de las líneas, las delicadezas de sus discretos acentos; la, fuerza expresiva de sus blancos realzada por la orquestación melódica de sus medias tintas de sus trazos entrecruzados. Nada hay de agitado ni nuevo en sus formas. Su tiempo no necesitaba de quién innovara, porque era un tiempo que cumplía su proceso de madurez y plenitud. Todo en su estilo es limpio, de una tranquila pureza, reflejo de corazón probo y una alma grande, pero 
también de un universo floreciente en su ascensión, en el que el hombre no había descubierto todavía plenamente su significado como individuo y cumplía su tarea dentro de las normas gregarias del alma colectiva.

A fuer de renacentista, fué al mismo tiempo que un pensador con ribetes de filósofo y escarceos ocultistas, un gran técnico. No se concibe, entonces la justificación de irregularidades en el estilo ni imperfecciones en la realización, por prejuicios de personalidad. Los altibajos justificados por el yo pasional del artista moderno, hubieran llenado de estupor al entendimiento riguroso de estos artesanos del genio.

Han transcurrido una centuria. El Renacimiento Italiano cumplió su ciclo vital, ahora es a su vez un sepulcro blanqueado en el que se refugian todas las senilidades.

De su pasión dominadora ha engendrado en la Academia, un vástago ecléctico, gesticulante y pomposo; el Manierismo, personajo viajero que invade con su gesto teatral y declamatorio, todos los circulos del buen gusto de la Europa de entonces.

En las tierras bajas de Holanda donde habita un raza flemática y fuerte, pacienzuda y pugnaz, la reacción antitaliana encuentra su más cabal personero, en el más grande de sus pintores: Rembrandt. De espaldas al discurso sonoro y teatral del Manierismo, él habla en su obrá un lenguaje sordo de tenebrosas raíces; hecho de púrpura y lodo, de oro y andrajos, como esos mendigos harapientos de colorida miseria, a los que su luz misteriosa, fueftemente concentrada en un punto presta un fulgor rutilante de gemas enela cenumbra."

Así es su vida: fantasmagoría. Así son sus obras: fantasmagoría, así es su técnica, la más extraña y misteriosa que paleta alguna haya tenido hasta entonces, cargada de aceites viscosos, de materias putrescibles, en la que los relieves del empastado hacía decir a sus contemporáneas perplejos, que sus retratos podrían colgarse por la nariz. Una mezcla de zaquizamí y palacio, de opulencia de la miseria y miseria de la opulencia, palpita en la obra inquietante del pintor de Leyden. Eń su obra grabada, reverbera el mismo espíritu al conjuro del más prodigioso manejo de los valores del rayado cuyas sutiles vibraciones de matices, hacen aparecer las transiciones del blanco puro, al negro más negro, que grabador algunuo haya logrado, como si el color hablara también en las monocromas estampas.

Rembrandt; es el genio inigualado del aguafuerte. Ni antes ni después hay quien lo supere. Así como en Durero el buril encontró intérprete, en Rembrandt, procedimientos y hombre, se encuentran y se 
completan. De no haber existido el pintor de Leyden, el aguafuerte estaría aún por lograr su plenitud.

¿Cómo fué el medio en que se desenvolvió sus facultades? Era un hombre del siglo XVII, hijo de la próspera Holanda, enriquecida con el tráfico colonial, cargada de las glorias de sus campañas de liberación. Al amparo seguro de un estatus político sólidamente constituído. $\mathrm{El}$ arte de este pueblo, es un arte civil de moderada dimensión, comenta preferentemente las contingencias de la vida corriente y diaria; se concreta al análisis de lo particular. Con Holanda, la pintura de género y el paisaje, estas dos manifestaciones del intimismo, alcanzarán una glorificación tal, que irradia hasta nuesiros días.

En las artes del grabado, se practica una técnica libre. Pero es a Rembrandt a quien le toca dar el carácter definitivo. En sus manos el punzón grabador atropella todos los procedimientos conocidos, donde los otros ponen moderación, él pondrá expontaneidad, audacia, fiebre. Sus nerviosos entrecruzados crean un universo de misteriosa penumbra, delicada, tenue, lóbrega, con lobregueces de caverna.

Son sus láminas, piezas que hay que gustar a la mano, si es posible con la ayuda de la lupa, que nos denuncie sus gradaciones apenas perceptibles, la exquisita calidad de sus matices, para sorberlos como un licor especioso, lenta, suave, voluptuosamente.

¿Cómo era el hombre? No tuvo la gregaria unidad de Durero. Fué un rebelde. Un rebelde en la dimensión que era posible en su tiempo. Fué un rebelde del espíritu. No se espere de ébl la gesticulación y el grito, porque su rebeldíg lo es en el plano individual hacia lo interno del ser. Fué vejado e incomprendido, no se quejó. En su obra nada se refleja de las contingencias amargas por las que tuvo que atravesar el hombre. El pintor vive ajeno a su problema externo como persona.

También fué un solitario. No se le ve unido a la figura de ningún príncipe, carece de brillo cortesano, si trató a personajes que posaron para él, fué en el plano del encargo, no figura entre los familiares y pecheros. Tampoco usufructuó de los favores del valido. Resistió al ambiente que dejó de comprenderlo, después de haberlo ensallado, sobrellevó con estoicismo el deshonor y la miseria finales.

Rompe el molde del pasado sin importarle los trastornos que esto le acarrea. Los encargos que comienzan a escasear, los amigos qus comienzan a huir, los discípulos que desaparecen, los mecenas que se retraen. Pero él, impasible, cotidiano en su esfuerzo que no detienen ni las más duras adversidades, abre las puertas y avienta al futuro, una nueva concepción de la pintura. 
31 de marzo de 1746. Hoy nace en un pueblecillo aragonés: Francisco Goya y Lucientes. De su paso por la vida desde ese dícr hasta su muerte el 16 de abril de 1828, en tierra francesa, nos queda un ejemplo de vitalidad asombrosa, identificada con el genio altivo, vivaz y contradictorio de su raza. Pero, cómo era aquella España que le trajo al mundo?

Era como fué, como es y como será. Tierra dura, donde del cielo parece más alto cual ninguno, lámina de pulido acero, de un gris azulado y dura luminosidad con rebrillo de navaja, Amarga en su rostro jaro, abrupta de contrastes, meseta y serranía, se enfrentan bruscas, perpendiculares, agrestes, como los ruinosos muros de esos castillos que levantan su amenazadora mole sobre las tierras resecas, solos, sin pueblo que les de calor, vigías de horizontes, guardianes celosos, místicos de la fuerza y la altivez, a lo, lejos unas casuchas parduzcas se recuestan a la sombra de chopos centenarios.

"Tierra vieja del cantil y la pena" le cantó García Lorca

La hermosa tierra de España

Adusta fina y guerrera,

Castilla de largos ríos

tiene un puñado de sierras

entre Soria y Burgos, como

réductos de fortaleza,

como yelmos crestonados

"Yurbión es una cimera.

Aquí en el verso de Antonio Machado, está el paisaje de España. Es verdad que no toda es así ¡ Oh dulces rías gallegas contorneadas de verdes colinas! ¡Valencia de huertas policromas! ¡Andalucía de plateados olivares! Vasconia, ondulada arcadia, con sus finos tipos de perfil silencioso.

Pero Castilla, si es así, ni más ni menos. Y Castilla da la pauta de España, le marca los caminos de su espíritu.

Parió esta tierra, una raza soberbia y viril. Soberbios y viriles los conocieron las legiones romanas, soberbios y viriles vivieron los sieto siglos de la reconquista; soberbios y viriles conquistaron a su vez un mundo, soberbios y viriles lo terminaron de perder, cuando marineros de modestos barcos de madera se enfrentan a los poderosos blindados yankis, en Santiago de Cuba. Sin sentido de la medida; pero con un hondo sentimiento de su propia dimensión, no les arredra empresa por 


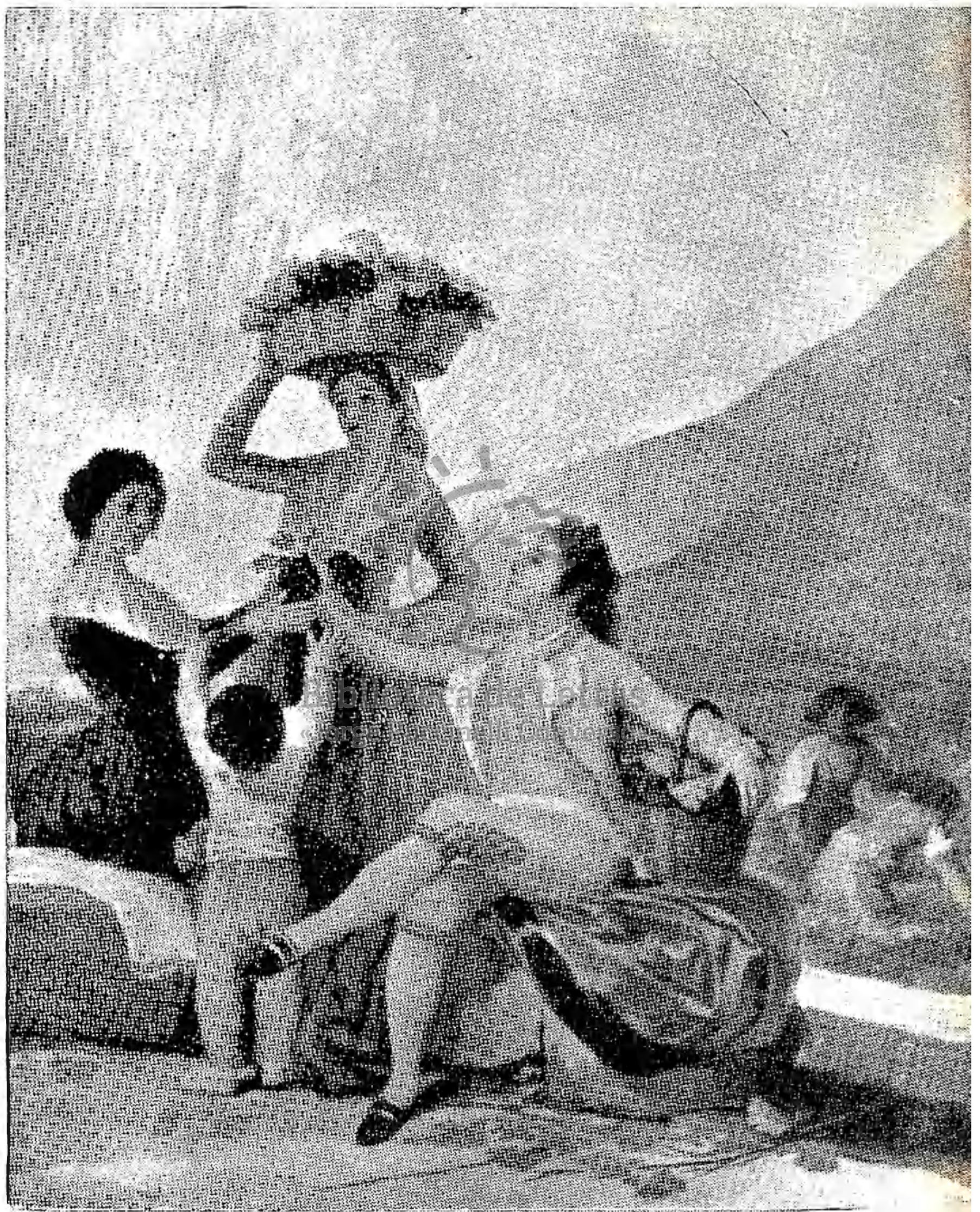




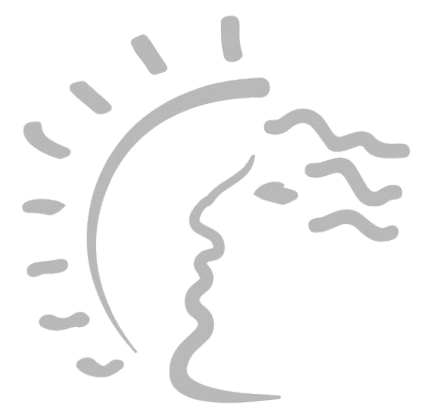

Biblioteca de Letras "Jorge Puccinelli Converso» 
riesgosa que sea. Su fatalismo, los arrastra precisamente a intentar lo imposible y a mirar más allá del aprovecho inmediato.

Vienen desde Numancia hasta el Madrid de nuestros días. Del Mio Cid Campeador al Empecinado y el cura Santa Cruz. Contra esto y aquello, con razón, o sin ella Santiago y a ellos. Así inconexos, sin lógica, muchas veces absurdos, pero siempre con rotunda grandeza, la individualidad española afirma su insofrenable voluntad de ser.

"Mis arreos son las armas, mi descanso es el pelear" canta el antiguo romance. Ser, Ser, Ser, aunque para ello no haya más descanso que el eterno pelear.

De ésta raza y de éste espacio geográfico nació Goya. Nos falta conocer su tiempo histórico.

Como era España en ese mediar del siglo XVIII en que su pintor más representativo viene al mundo?

Reinan los Borbones españoles, descendientes del Rey Sol, rama debilitada y decadente, "las enjuagaduras del vaso" tal como les calificara el malicioso médico real, a los hijos legítimos de Luis XIV, cuya exigua salud contrastaba con la normal vitalidad de sus bastardos.

España y su capital viven en esos días sin embargo, una fugaz ilusión de renacimiento bajo las sagaces manos italianas de Alberoni, ministro de Felipe V. El sucesor, Carlos III, es un hombre cultivadó y discreto, buen gobernante, "rara avis" en esa colección de ineptas personas reales. Reorganiza la vida española; crea bajo los auspicios del despotismo ilustrado, una era de prosperidad y buen sentido. No en vano, es él, medio francés por sangre y medio italiano por educación y gobierno. Carece del gusto nacional por los extremos, mantiene su gestión gubernativa en la senda del equilibrio, como un certero fiel de balanza entre la apasionada vitalidad del pueblo que le toca gobernar y las razonables normas de progreso al alcance de su tiempo.

La capital se asea y se embellece, se moderniza la administración, ese mounstruo pepelero que hiciera un siglo antes escribir a Góngora su resentimiento contra la morrallería curialesca de la corte bajo los Austrias "Madrid, mentiras arbitreras... abogados".

Florecen las industrias, no hay guerras ruinosas en las fronteras. Las colonias de ultramar viven su maduramiento, y contribuyen regularmente a sanear la hacienda pública. Nada hace suponer todavía las convulsiones libertarias.

La vida cultural toma los peinados caminos de la academia, al estilo galo. España se afrancesa. Francia es, al mundo europeo de esos días, lo que fuera Italia dos siglos antes, en el Renacimiento, su gusto 
impera como norma orientadora en todos los aspectos. Se vive a la francesa, se piensa a la francesa, se pinta a la francesa.

¡Feliz siglo XVIII! tan vilipendiado por quienes no quieren ver en él sino su hedonismo galano y su arte de boudoir; pero olvidan que fué también el siglo de las luces, el siglo de la Enciclopedia y los derechos del hombre.

Es verdad que de su frivolidad risueña, surgieron las mascaradas de Lancret; y las complacencias de Crebillón, las fruslerías de Boucher y las melosidades galantes de Fragonard. Pero también supo dar vida al arte exquisito de Watteau y a la serena belleza de Chardin; al espíritu crítico de Voltaire y al pensamiento rector de Diderot.

¿Cómo sería Madrid en esos días? Aun hoy lo podemos avisorar, porque esa ciudad conserva mucho de su antiguo espíritu. No es el alma de España, porque esa alma está en Toledo. No es la gracia de España, porque esa gracia está en Sevilla, no es la mano industriosa de España, porque esa mano está en Bilbao y Barcelona, no ess la mente de España, porque esa mente está en Salamanca, no es la más antigua raigambre de España, porque esa raigambre está en Burgos, Segovia, Avila, pero es todo eso al mismo tiempo. Porque del señorío toledano tiene su castellanidad altiva, de la gracia sevillana, tiene el garbo castizo, lo necesario del espíritu industrial barcelonés y bilbcíno pero nada más que lo necesario para no perder su inconfundible silueta. Del ajetreo intelectual de Salamanca lo suficiente para tener categoría primerísima. En cuanto a la raigambre la historia de sus calles y las calles de su historia, muestran las cicatrices" de su alma heroica.

De su espíritu dieciochesco, nos informan mejor que nadie las comedias de Moratín y la admirable serie de los cartones que pintara Goya para la real Fábrica de Tapices. Es un mundillo popular y chulapo, el que bulle por las callejas de la Villa del Oso y del Madroño.

Rinconete y Cortadillo, ahora adultos y en Madrid, visten calzón de seda y chaquetilla con caireles rococó. También está el señor Manipodio y Guzmán de Alfarache, oh eterno presente de la picaresca, paradógica contraparte española del misticismo y la épica.

Un saborcillo gabache, alegre y retozón sazona sus existencias. Estamos lejos de los negros rebozos y las negras vestiduras del anterior siglo. Ahora, son los alegres tonos vivaces los que circulan, como esas vistosas capas punzó que tan discretamente disimula la sangre de los navajazos.

Vida alegre colorida y vistosa como el paseíllo de la cuadrilla antes del drama taurino. Pero suena el clarín sale el toro a la arena. 
La alegre y algarabiente multitud calla y se crispa. Fuera gente para mi solo, todo el ruedo y ahí comienza el drama espectacular y tremendo.

Tauromaquia de la historia, capricho y disparates los desastres. "El sueño de la razón produce mountros", "iqué valorl" "duro es el paso", "para eso habéis nacido", "no se puede mirar" y " no hay remedio".

"La virgen del Pilar dice que no quiere ser francesa, que quiere ser capitana de la tropa aragonesa". Así cantaba el pueblo en aquellos días de la epopeya anti-napoleónica.

Cantares del Pueblo español lo acompañaréis siempre cuando la pólvora y la sangre, hechos populacho y cólera, se desbordan por las calles madrileñas, bajan como enfurecido torrente hacia la Puerta del Sol, corazón palpitante de la villa Guzmán de Alfarache. Rinconete y Cortadillo están ahí, también el señor Manipodio. Oh heroica contraparte de la picaresca. Se arroja con furia ciega contra la caballería francesa, sin más armas que su coraje, palos y navajas. Es su hora de la verdad, hacia su destino entran derechamente, sin voltear la cara.

En esos instantes frenéticos, un hombre los está mirando, les co. noce, estuvo con ellos en la "pradera de San Isidro" y en las fiestas del "árbol de mayo". Participó de su alegría carnavalesca en el "entierro de la sardina" y hasta fueron compañeros de brega por las capeas de provincia. Es verdad, que de eso hace muchos años. Ahora es un personaje importante, un paniaguado de la corte, pintor de cámara del Rey y por ende, afrancesadoodeeideas Rinconete y Cortadillo. El señor Manipodio, Guzmán de Alfarache Y muchos otros, están ahora en las afueras de la villa, en el lugar conocido como Montaña del Príncipe Pío, monte calvario del patriotismo madrileño. Es de noche, han pasado apenas unas cuantas horas de la gesta heroica e inútil por que el valor civil no pudo vencer a la milicia organizada.

Sobre el fondo oscuro del cielo nocturno, se dibuja borrosa la silueta de la ciudad. Un farol recorta con su luz blancuzca el torvo perfil del pelotón de fusilamiento, ayes, gemires, terror y cadáveres, coágulos sanguinolentos, revoltijos. Se tronchan sobre sus piernas los que van a ser muertos pero en el centro del grupo hay uno. Ese uno que es el alma misma de la raza, se yergue sobre las dobladas rodillas y le. vanta los brazos. ¿Es Rinconete, es Cortadillo?, no lo sabemos, sólo se oye su grito. Ese grito que absorbe toda la luz de la escena, como encarnando en su vocear iracundo, la sobrevivencia de lo que no muere, aunque lo maten. Grita desde el pasado hacia el futuro, grita desde su luz, contra la sombra que quiere apagarle. Su grito retumba en los ecos hasta el corazón de ese hombre que los conoce y los está mirando. 
Es sordo el pintor de cámara de su majestad católica. Es sordo desde que un accidente de carretera le cerrara los oídos al mundo de los ruidos, pero felizmente para el arte no es ciego. Por sus ojos prodigiosamente dotados el grito lo penetra como una lanza de fuego, le hierve la sangre, acorrala en su interior al académico, al valido, al pintor do las majezas de la chulería y las chulerías de la majestad.

El tiene mejores armas para luchar y más perdurables, además una deuda tremenda que saldar, va a pagarla y en qué forma. Ahí, en el museo del Prado están. "La Carga de los Mamelucos en la Puerta del Sol" y "Los fusilamientos en la Montaña del Príncipe Pío".

Tenía 62 años cuando el drama lo arrastra en su turbión. Data de esa época su aislamiento en la "quinta del sordo", como llamaban a su casa situada en las afueras de Madrid, algo más allá de la puerta de Segovia. Fué ahí seguramente donde inició los bosquejos de la serie de sus "Desastres de la Guerra", la obra grabada que más lo caracteriza.

Ya anteriormente produjo los "Caprichos", más tarde grabará los 'Proverbios y Disparates", remanso de sus angustias será la serie de ia Tauromaquia, pero es en "los Desastres" donde el hombre y el procedimiento, encuentran su lenguaje adecuado. En los "Caprichos" el tema es estrictamente de crítica. Goya, pintor mundano, hombre sometido a los caprichos de la frivolidad cortesana se venga en sus grabados. Es su problema íntimo, el que proyecta contra la estupidez y la estulticia. Más candentel yo tersonal aún, éesultan aquellas planchas que graba, como quien escribe libelos, contra la amante infiel y esquiva.

De su punzón amargado por la traición, de quien estaba demasiado alto para poder ejercer otra clase de venganza, surgen generalizaciones que van desde la desesperada imagen del hombre enamorado en "El sueño de la Razón produce Monstruos" hasta aquellas de alusión directa como "El Sueño de la mentira y la inconstancia".

Las coquetas del paseo del Prado y los petimetres a la moda, tiene en su ironía una fusta implacable. Recuerda en su dureza al caústico Conde de Villamediana, quien refiriendo al mismo paseo del Prado bajo Felipe IV escribiera aquello "Prado amado, duéleme verte pisado, por aquellos que debieras ser pacido".

Nadie refleja más fielmente los contrastes del temperamento español que este aragonés tremendo. $Y$ es en su obra grabada donde está más íntegro, donde el hombre es más verdad.

No hay que olvidar que los grabados no son encargos, no están pues condicionados, al gusto del mecenas. Es en ellos donde él busca dar rienda suelta a su pensamiento íntimo. Mientras este pensamiento 
es tan sólo el exponente de sus vicisitudes personales, no alcanza su mayor nivel.

Tiene que llegar al lacerante anatema de los "Desastres de la Guerra" para encontrarse asimismo, depurar la dicción de los elementos innecesarios y hallar toda la potente simplicidad de su estilo.

Prescindiendo de su temática por el momento para estudiarlo desde el punto de vista de lo técnico, Goya comparado con Rembrandt es elemental. No se sorprendan Uds. por esto que parece una herejía, pues en ello reside precisamente su grandeza.

No alcanza el español la riqueza de matices ni la mórbida belleza de las calidades del holandés, ni tiene el profundo conocimiento de los efectos posibles del rayado y los mordientes.

No lo necesita tampoco. En sus primeros grabados, la serie de los caprichos todavía está dentro de las preocupaciones del oficio.

Más tarde él crea su técnica, la justamente necesaria para su propósito. Es en esto en el propósito en donde hay que buscar la razón de su estilo, un tanto simple, en el que se alivia precisamente con el uso de la aguatinta, para simplificar el trabajo y los efectos. El no entrecruza los rayados $\mathrm{nol}$ no busca construir, ni crear atmósfera, se limita a subrayar con trazos paralelos, para obtener la imagen y darle dinamismo. Eso lé basta y con eso basta también.

Porque no se proponía crear bellas estampas ni estampar belleza, su propósito fué ilustrar hechos. Por eso sus grabados valen más por lo que narran, que poroél como lo narra. Su tremenda fuerza está en lo expuesto, no en la forma de exponerlo.

Es ahí donde reside la fundamental diferencia, por situarse en ese terreno es que Goya se puede dar la mano con Rembrandt, de otro modo estaría muy por debajo. No es pues una diferencia de condiciones lo que los separa y los nivela al mismo tiempo sino una diferencia de propósitos.

El de Holanda, vive en tiempo histórico muy diferente al del aragonés. Ni Leyden es Fuendetodos; ni La Pradera de San Isidro, Sheveninguen. Igualmente, el mundo español contemporáneo a la Revolución francesa, no podía tener los mismos ideales ni los métodos expresivos de la Holanda del siglo XVII.

Esta lo que quiere, es la búsqueda de lo particular y privado, ahondar, con idealismo nórdico, controlado por la tranquila meticulosidad de su genio nacional equilibrado. Rembrandt, comparado con sus compatriotas, aparece como un inquieto de mano rebelde a las normas, un indisciplinado genial. Comparado con Goya, resulta estático, 
medido, mesurado en los ademanes, nada gesticulante, menos aún verboso en el discurso.

Los grabados del aragonés son anotaciones rápidas, nerviosas, meridionalmente elocuentes, en las que busca registrar lo patético de un hecho, simplificando todo lo que no sirva puramente para resaltar el tema. Cuando no apela al recurso fácil de los fondos cerrados a la aguatinta, ellos son someras anotaciones de arquitectura $\circ$ parajes apenas esbozados.

Es en estos negros uniformes de los fondos donde más se diferencia con el holandés. Bueno es compararlos. En Rembrandt, los negros profundos densos y sin embargo transparentes. Llega a tal grado su virtuosismo, que en algunos grabados a primera vista sombríos, nos descubren a la indagación minuciosa, todo un mundo misterioso y palpitante de detalles inmensos en la penumbra.

En Goya los negros son netos, duros, no envuelven la imagen sino la limitan y la proyectan directamente contra el observador. Ellos contribuyen a destacar, nunca a fundir y velar.

Los comentarios a guisa de títulos que se agrega al pie son una demostración más de su deseo. El se interesa que comprendamos lo que describe, no por la belleza de su forma, que casi siempre es horrenda, sino por su significación humana. Aun en aquellos que nos resultan herméticos de sus caprichos y sus disparates, la imagen aparece siempre nítidamente trazada.

Por eso, por estavioluntad de Gmprecarly protestar, recurre al registro de todo lo maçabro Y teratológic que hay en su derredor, luego cuando el cruento drama de la guerra se desata, se abalanza a hurgar en lo más repulsivo, para gritarnos "No se puede Mirar" y en seguida, "Yo lo ví" podría haber agregado, ahora véanlo Uds.

En cambio Rembrandt, pertenece a otro mundo mental, a otro tiempo, le preocupan otros problemas. El vió también miserias y las pintó. La guerra que siempre es igual en su bestialidad, no le pudo ser ajena; pero su sensibilidad no podía responder por razones de su educación y costumbres, en otra forma de como lo hizo. No había aparecido aún en el hombre, la conciencia ciudadana de la libertad y el derecho individual. Ciertamente los horrores repugnaban; pero el sentido de la justicia era otro y la aceptación de la violencia también.

En su obra Rembrandt no busca confundir, ni aleccionar, ni predicar. Elige un tema cualquiera como pretexto, por ejemplo "Jesús Curando a los Enfermos".

Un amplio espacio interior, de un edificio algo ruinoso. En el centro, un hombre habla, a su derredor, una multitud de dolientes se arras- 
tra, otros personajes aparentemente espectadores del milagro, rodean al maestro. Indiferentes unos, curiosos otros, escépticos algunos, simples figurantes los demás. Ni el Redentor ni los que le rodean tienen nada de particular, apenas si sus vestimentas los diferencian. ¿Dónde está pues la pretendida grandeza de ésta estampa tan modernamente compuesta? ... En la luz.

En esa luz, que es el maravilloso universo privada de Rembrandt Esa luz que al conjuro de la maestría inigualada de su mano, irradia con su halo de misterio, desde la figura del Redentor. Surge como un chorro silencioso del blanco del papel, envuelve tiernamente los contornos, destaca algunos personajes apenas delicadamente dibujados, se intensifica en blancores exquisitos y se retira, en las penumbras del fondo, hasta los más extremos límites del debilitamiento, sin llegar nunca a la opacidad inexpresiva.

Esta es la labor genial de un grabador nato. La escena podía ser otra cualquiera, no es en ella donde reside el interés, es apenas un pretexto, para crear en el espacio reducido de la lámina, ese universo de tenues calidades calibradas hasta lo increíble.

Rembrandt, hombre del pasado, está dentro del concepto de la vida para y por el Arte. Goya hombre moderno, cree que es el Arte quien está al servicio de la vida.

Tal modernidad está patente en lo mucho que hay de información y comentario periodístico en sus grabados. Su apasionado deseo de registrar el acontecimiento, de conservarlo para la posteridad, de sacar una moraleja de suevisión.inelli Converso"

Vibra ya en él, la emoción social, que hace presumir las inquietudes del futuro. No vive y produce para el Arte. Produce Arte para hacer vivir sus ideas.

Rembrandt, hombre inmerso en el ideal colectivo de su época, trabaja en el solitario y personal problema del ahondamiento de su individualidad, afirmándola.

Goya, individualista acérrimo, viviente en un.mundo en el que el yó persona, recaba su independencia y su derecho, se vuelca en los intereses colectivos, se identifica con la humanidad, asume el partido de la verdad y la justicia, desenmascara las farsas de la superstición, arroja a la faz de los poderosos la acusación de su egoísmo y la injusticia de su usufructo.

El no podía para tales propósitos emplear otra técnica que la que empleó. Por otra parte ¿qué es la técnica?. No por supuesto el hábil y miope manejo de fórmulas conocidas y operantes en pasadas realidades: esto no es técnica sino academicismo. Técnica es la perfecta ade- 
cuación de las posibilidades del oficio a un uso personal acorde con los propósitos de la voluntad de creación.

Si Goya, como lo hace en sus primeros grabados, se hubiese enfrascado en especulaciones valorísticas con una pura finalidad estética, de acuerdo a los cánones, hubiera sido un grabador algo más original que sus contemporáneos. Carecía de frescura y espontaneidad. Sus ideas nos llegarían, trabajosamente pronunciadas, borrosas, se perderían en una sordina, que se aviene mal con las necesidades de su discurso.

Fué, lo que debía ser. Al igual que Rembrandt, quien usando los métodos expeditivos de Goya, resultaría superficial e intrascendente. La técnica de cada uno fué la precisa, a las finalidades de su mensaje.

El español logró con su potente garra moderna, cerrar en un espacio triangular el universo del grabado. Quede conformada así la altísima trinidad del arte de grabar.

Alberto Durero el padre genitor, Rembrandt van Rjin, el hijo anunciador de la nueva doctrina salvadora, Francisco Goya el espíritu alto encarnado en águila real. Tres personas diferentes en una sola categoría verdadera.

De los tres, el que está más cerca de nuestro sentimiento es Goya, porque en él palpita un mensaje permanente, una norma de actividad, una fuerza de proximidad, de parentesco en el problema y en la sangre, con nosotros hijos de ésta tierra americana la palabra América tiene en nosotros su auténtica validez, porque somos una raza antigua y ambidextra, con una rárzindiay olra española. Nuestra fuerza potencial no reside en los rascacielos bancarios, sujetos a las contingencias financieras de la quiebra. Está ahí, viva y esperando en los ciclópeos muros de Saxahuamán, en los tallados frontispicios de nuestras catedrales. Por que ellos son espíritu y el espíritu no quiebra.

Francisco Goya, emocionados y contrictos recibimos tu mensaje. Tú nos das el más claro ejemplo de lo que puede el arte de una raza cuando ésta quiere SER, Ser, SER ese también nuestro problema, no aquello ni lo otro sino nosotros mismos.

iOh altos roquedales de los Andes, donde el cóndor asienta su garral Oh piedras de Guisando donde pastan milenarios los toros ancestralesl Dadnos la fuerza para resistir a todas las contaminaciones. A tí Goya te agradecemos tu voz y tu visita. Te queremos abrazar en las personas de estos tus representantes los artistas grabadores españoles, que tan airosamente portan tu mensaje y a quienes desde ésta Lima nuestra les decimos para que te lo trasmitan ...

Bien venidos señores y muchas gracias. 